\title{
Estimating cancer risk in relation to tritium exposure from routine operation of a nuclear-generating station in Pickering, Ontario
}

\author{
S. Wanigaratne, MHSc (1, 2); E. Holowaty, MD (2); H. Jiang, MSc (1); T. A. Norwood, MSA (1); \\ M. A. Pietrusiak, MHSc (3); P. Brown, PhD $(1,2)$
}

This article has been peer reviewed.

\begin{abstract}
Introduction: Evidence suggests that current levels of tritium emissions from CANDU reactors in Canada are not related to adverse health effects. However, these studies lack tritium-specific dose data and have small numbers of cases. The purpose of our study was to determine whether tritium emitted from a nuclear-generating station during routine operation is associated with risk of cancer in Pickering, Ontario.
\end{abstract}

Methods: A retrospective cohort was formed through linkage of Pickering and north Oshawa residents (1985) to incident cancer cases (1985-2005). We examined all sites combined, leukemia, lung, thyroid and childhood cancers (6-19 years) for males and females as well as female breast cancer. Tritium estimates were based on an atmospheric dispersion model, incorporating characteristics of annual tritium emissions and meteorology. Tritium concentration estimates were assigned to each cohort member based on exact location of residence. Person-years analysis was used to determine whether observed cancer cases were higher than expected. Cox proportional hazards regression was used to determine whether tritium was associated with radiation-sensitive cancers in Pickering.

Results: Person-years analysis showed female childhood cancer cases to be significantly higher than expected (standardized incidence ratio [SIR] $=1.99,95 \%$ confidence interval [CI]: 1.08-3.38). The issue of multiple comparisons is the most likely explanation for this finding. Cox models revealed that female lung cancer was significantly higher in Pickering versus north Oshawa $(\mathrm{HR}=2.34,95 \% \mathrm{CI}$ : 1.23-4.46) and that tritium was not associated with increased risk. The improved methodology used in this study adds to our understanding of cancer risks associated with low-dose tritium exposure.

Conclusion: Tritium estimates were not associated with increased risk of radiationsensitive cancers in Pickering.

Keywords: cancer, tritium, nuclear power plant, historical cohort study

\section{Introduction}

According to a survey conducted in 2012 for the Canadian Nuclear Association, $55 \%$ of the Canadians surveyed think that "danger- ous" describes nuclear energy extremely well or very well. ${ }^{1}$ This perception may stem from studies that found elevated risks of adult cancers resulting from high levels of exposure to radiation ${ }^{2}$ experienced by survivors of the nuclear bombs dropped on Japan in WWII or from events such as the Chernobyl nuclear disaster. On the other hand, reviews examining risk at low levels of exposure, conditions consistent with working in the Canadian nuclear industry, suggest increased risks are possible but undetectable. $^{3-6}$

The developing fetus is particularly sensitive to radiation effects. As such, all childhood cancers and leukemia are a concern even at low levels of exposure. Several studies have been conducted on childhood leukemia near nuclear power plants (NPPs). ${ }^{7-9}$ Most reported no increased risk. Recent case-control studies in Germany ${ }^{10,11}$ found that the risk of childhood leukemia (age $<5$ years) doubled within $5 \mathrm{~km}$ of German NPPs. The reasons for this increase remain unclear. ${ }^{12}$ Studies in France, ${ }^{13,14}$ Britain ${ }^{15}$ and Finland ${ }^{16}$ did not find increased risks.

The uncertainty around health effects from low-dose exposures is related to the small numbers of cases and the lack of tritiumspecific dose data in these studies. This uncertainty contributes to the continued public concern in communities near NPPs.

The Pickering Nuclear Generating Station (PNGS), along with most of the city's population, is in the southern part of Pickering, Ontario, a municipality east of the city of Toronto with a population of 87 838. ${ }^{17}$ PNGS began operating in 1971 and decommissioning is planned for 2020 .

Author references:

1. Cancer Care Ontario, Toronto, Ontario, Canada

2. Dalla Lana School of Public Health, University of Toronto, Toronto, Ontario, Canada

3. Durham Region Health Department, Whitby, Ontario, Canada

Correspondence: Susitha Wanigaratne, Cancer Care Ontario, 620 University Avenue Suite 1500, Toronto, ON M5G 2L7; Tel.: 416-971-9800 x 3609; Fax: 416-971-6888;

Email: susitha.wanigaratne@cancercare.on.ca 
PNGS consists of two distinct stations, A and B, each with four Canadian Deuterium Uranium (CANDU) reactor units, two of which were shut down in 1997. CANDU and other heavy water reactors (HWRs) comprise a small proportion of nuclear reactors worldwide, operating in Canada and several other countries. ${ }^{18}$ HWRs emit one or two orders of magnitude more tritium (per gigawatt of energy produced) than any other type of nuclear reactor. ${ }^{19}$ Tritium is a by-product of routine operation, emitted mostly as tritiated water vapour (HTO), and its decay results in emission of beta radiation. ${ }^{20}$ Tritium constitutes $99 \%$ of all radioactive emissions from PNGS. $^{21}$ PNGS provides a unique opportunity to examine cancer risks in a large urban population that may arise from low-dose radiation exposure from tritium emissions.

HTO can be inhaled, absorbed through the skin or ingested and can be incorporated into organic molecules in the body as organically bound tritium (OBT). ${ }^{3}$ Dose estimates referred to or calculated in this study include contributions from both HTO and OBT. Estimates assume that $97.8 \%$ of tritium entering the body as HTO remains as HTO (half-life of 9.7 days) and $2.2 \%$ is converted to OBT (half-life of 48.5 days). ${ }^{3}$ Human cells that reproduce quickly are especially sensitive to ionizing radiation.
In 2011, the total radiological dose resulting from the operation of PNGS was estimated to be $0.9 \mu \mathrm{Sv}$ for an urban resident in the Pickering and Ajax area ${ }^{22}$ (see Figure 1). This is well below the public dose regulatory limit of $1000 \mu \mathrm{Sv}$ /year. It also represents $0.1 \%$ of the $1400 \mu \mathrm{Sv}$ naturally occurring annual radiation dose near PNGS, or $8 \%$ of the $12 \mu \mathrm{Sv}$ dose from two hours of airplane travel. $^{22}$

The purpose of our study was to determine whether tritium emissions from routine operations at PNGS were associated with higher risk of radiation-sensitive cancers in Pickering, Ontario. Our three objectives

FIGURE 1

Study areas, PNGS tritium dispersion surface and location of nuclear power plants, Pickering, Ontario, and Oshawa, Ontario

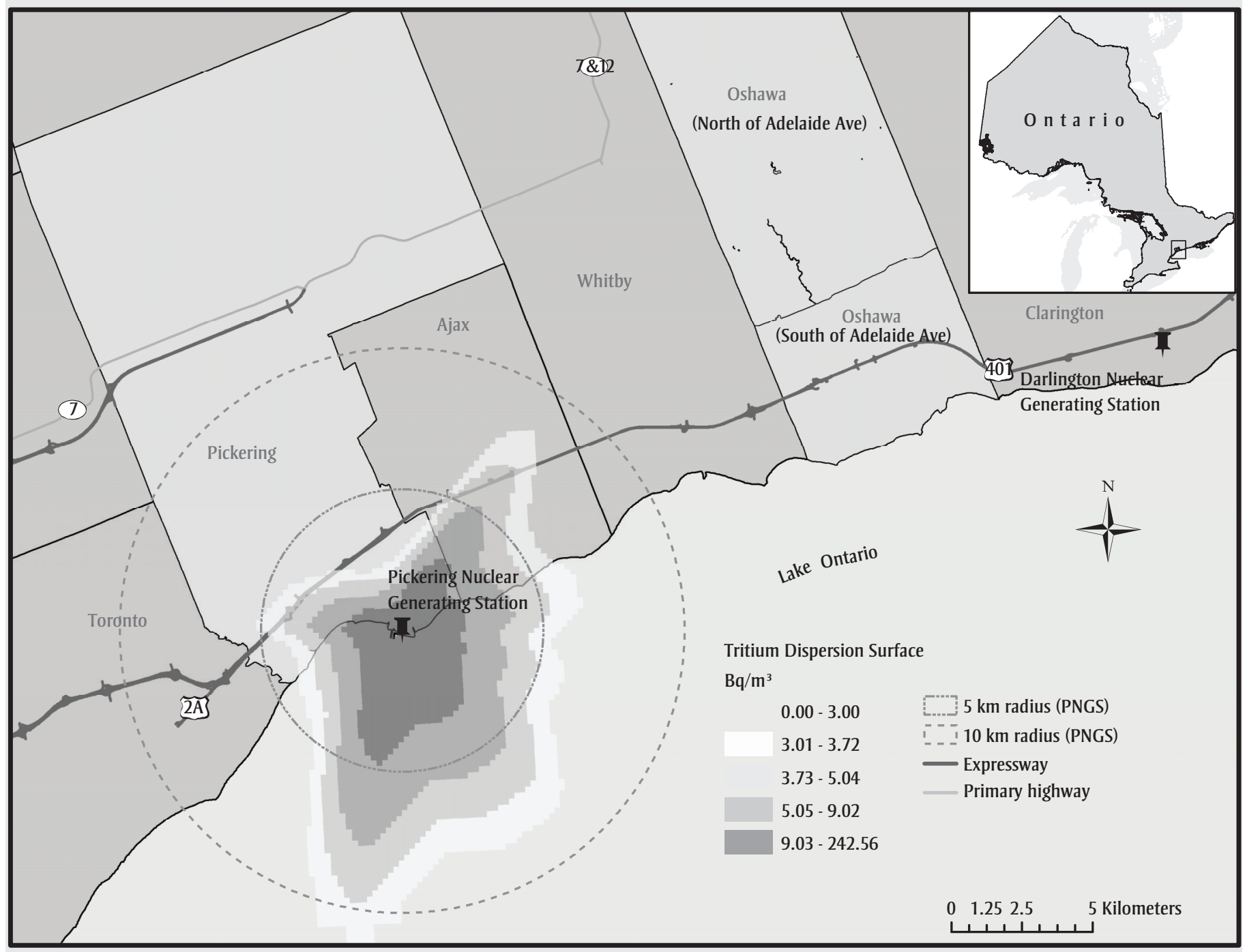

Abbreviation: PNGS, Pickering Nuclear Generating Station. 
were to: (1) evaluate the health of the cohort of Pickering residents by comparing the observed cases of cancer to the expected number of cases given cancer rates in all Ontario; (2) determine whether tritium estimates explain cancer risk among Pickering residents compared with residents of north Oshawa; and (3) determine whether tritium estimates are associated with cancer risk among Pickering residents exposed to stable tritium ("nonmovers," resident at the same address for the previous 6 years). Our study minimized the limitations of previous studies by using tritium estimates based on actual emissions data as well as a population-based retrospective cohort with sufficient follow-up and a large sample size.

\section{Methods}

A 20-year retrospective cohort including residents of Pickering $(n=36805)$ and north Oshawa ( $\mathrm{n}=43$ 035, comparison population) in 1985 followed forward for cancer incidence and mortality until the end of 2005. These data were analyzed in two ways: person-years analysis (objective 1) and Cox proportional hazards regression (objectives 2 and 3 ).

\section{Data sources}

\section{Pickering and north Oshawa property assessment files (PAFs)}

The Durham Region Planning Department provided 1979 and 1985 property assessment files (PAFs) for the cities of Pickering and Oshawa ( $\mathrm{n}=162$ 986). These files contained the surname, given name(s), birth year, birth month, full address and postal code of each person living in the region. These files were securely transferred to the study investigators and were stored on a secure server at Cancer Care Ontario. Analysis of the cohort excluded those residents aged 5 years or less and 85 years or more since these age groups were underrepresented in the PAF.

We tried to increase the sample size and distribution of exposures by including a large comparison population with no tritium exposure. We chose north Oshawa because we were limited to municipalities for which we had the PAF
(Durham Region) and we needed a population similar to Pickering but far enough away from both PNGS and the Darlington Nuclear Generating Station (see Figure 1) to minimize tritium exposure.

Members of the 1985 Pickering cohort living in the same residence for the previous 6 years (non-movers) were identified through deterministic linkage to the 1979 PAF. We assumed the stability of non-movers' residence and therefore assumed more stable tritium exposure in comparison to the rest of the cohort. Nonmovers were analyzed separately.

Additional information on data quality and data preparation, including linkage methodology, is available from the authors on request.

\section{Ontario Cancer Registry}

We obtained incident cancer cases for this study from the Ontario Cancer Registry (OCR). The OCR captures all new cases of invasive neoplasia, except for non-melanoma skin cancers, in the province of Ontario. $^{23}$

The 1985 Pickering and Oshawa PAFs were probabilistically linked ${ }^{24}$ to the OCR to determine incident cases of cancer diagnosed from 1 July 1985, to 31 December 2005. Cohort members diagnosed with cancer contributed persontime until their diagnosis date.

Cancers were chosen a priori based on evidence from moderate-to-high dose studies that achieved reasonable statistical power and precise estimates. ${ }^{2}$ Elevated risks were substantial for leukemia and especially pronounced for those exposed at a young age. Female breast, thyroid and lung cancers were also elevated. A review supported the linear extrapolation of these results to low-dose scenarios. ${ }^{25}$ All cancers combined were examined for comparison. The relevant International Classification of Diseases, $9^{\text {th }}$ revision (ICD-9) diagnosis codes were 140 to 239 (all cancers), 162 (lung), 174 (breast), 193 (thyroid) and 204 to 208 (leukemia).

\section{Vital Statistics - Mortality Data ${ }^{26}$}

These data were used to remove cohort members who had not been diagnosed with cancer but who died from any cause within the follow-up period (1985-2005). These subjects contributed person-years until their date of death. The Pickering and Oshawa PAFs were probabilistically linked to these data.

\section{PNGS modelled tritium estimates}

To characterize the spatial distribution of tritium originating from PNGS, we implemented the AERMOD Gaussian atmospheric dispersion model. ${ }^{27}$ Average regional meteorological data observed at Toronto Pearson International Airport (1996-2000) and facility characteristics that included average annual tritium emissions reported by Ontario Power Generation (1994-1998) were incorporated into the model, as were the velocity and temperature of the emissions. Atmospheric tritium radiation levels were estimated in becquerels (one unit of radioactive decay per second) per cubic meter $\left(\mathrm{Bq} / \mathrm{m}^{3}\right)$ for each unit in a spatial grid $50 \mathrm{~km}$ by $50 \mathrm{~km}$ that covered the study area. Tritium estimates were assigned to each cohort member based on the value calculated for the grid cell that overlapped the exact residential address as indicated in the 1985 PAF (see Figure 1 for tritium dispersion surface).

\section{Average annual household income}

We used average household income as a proxy for smoking ${ }^{28}$ and adjusted for this in the analyses. Average household income was assigned as a continuous variable to each cohort member using the average household income in 1990 as recorded by the 1991 Census at the enumeration area $^{29}$ level. The 1991 Census was the earliest time for which average household income information was released at this fine spatial level. Individual income information was not available.

\section{Analytical methods}

\section{Person-years analysis}

For objective 1, we undertook a standard person-years analysis ${ }^{30}$ of the Pickering and north Oshawa cohort to estimate standardized incidence ratios (SIRs) by five-year periods (1986-1990, 1991-1995, 
1996-2000, 2001-2005) and assess differences over time as well as over the whole time period (1986-2005). We conducted this analysis to assess the overall health of the cohort in comparison to a standard population.

We used the LEXIS SAS macro ${ }^{31}$ to calculate person-years for the specified time periods for Pickering residents, Pickering non-movers and north Oshawa residents, by major cancer site (all sites combined, female breast, leukemia, lung, thyroid and childhood cancers combined for 6-19 years), sex and 5-year age group. The childhood cancers combined category was limited to 6 to 19 years due to PAF exclusions (see "Data Sources" section). We obtained cancer rates by sex and 5-year age group for Ontario from SEER*Stat ${ }^{32}$ (data available from 1986 onwards) for the time periods specified. Site-specific expected counts were calculated by multiplying sex- and age-stratified person-years for each cancer site by Ontario age-specific cancer rates. ${ }^{33}$ Expected (E) and observed (O) counts were summed across age groups and overall SIRs (O/E) and mid- $p$ exact confidence intervals (CIs) were calculated ${ }^{34}$ for Pickering residents, Pickering nonmovers and north Oshawa residents.

\section{Cox models}

We conducted Cox proportional hazards regression $^{35}$ with $\mathrm{R}$ version 2.13.2 (R Foundation, Vienna, Austria) to address objectives 2 and 3. Cox models are preferred for time-to-event analysis over other statistical methods in the epidemiological literature for several reasons, the most often cited being that specifying a probability distribution for follow-up times is not required. ${ }^{36}$ Models focused on male and female lung cancer and female breast cancer. We could not analyze thyroid cancer and leukemia in the cohort due to small sample sizes. ${ }^{37}$

Two exposure scenarios were tested: one where Pickering (higher tritium concentrations) was compared with north Oshawa (low tritium concentrations) with risk estimates adjusted for tritium concentration; the other where risk of cancer associated with increasing tritium concentration was examined in a model limited to Pickering non-movers. Given a sample size of about 18000 exposed (Pickering) and about 22000 unexposed (north Oshawa), we have $80 \%$ power to detect: (1) a doubling of breast cancer risk; (2) a 2.5 times increase in female lung cancer risk; and (3) a 2.4 times increase in male lung cancer risk. Considering the much smaller sample size in the Pickering nonmover analysis, these analyses are underpowered. We note that obtaining adequate sample sizes is a common problem in this area of research; however, we stress the unique character of this study in examining cancer risks from tritium exposure in a sizeable population-based cohort.

In all Cox models, age was used as the time scale ${ }^{38,39}$ rather than follow-up time to (1) more efficiently adjust for the nonparametric effect of age, taking into account the risk of cancer increasing non-linearly with age ${ }^{40}$ and (2) put subjects with similar risks, related to age, in a risk set together rather than forming the risk set based on subjects with similar follow-up time. ${ }^{41}$ The hazard ratio (HR) in these models is interpreted as an agespecific risk rather than a time-specific risk. ${ }^{39}$

We assumed that average annual household income would confound the relationship between tritium exposure and cancer, and therefore we did not formally build models. ${ }^{42}$ Non-linearity of tritium exposure and average household income were accommodated by creating a changepoint* at the average values of $2.9 \mathrm{~Bq} / \mathrm{m}^{3}$ and $\$ 64725$, respectively. HRs and associated $95 \%$ CIs for tritium were associated with a unit increase in tritium exposure. Non-normality of average household income was corrected by square root transformation of standardized values. HRs and associated $95 \%$ CIs for average income were associated with a $\$ 10000$ increase in income. Interactions between income and tritium exposure were also tested and retained only if significant $(p \leq .05)$. Models were also adjusted for frailty, taking into account potential clustering of cancer risk in adjacent census tracts. ${ }^{43,44}$
The study received ethics approval from the Ontario Cancer Research Ethics Board. Access to OCR and Vital Statistics Mortality data was approved by the Data Access Committee at CCO. The Durham Region Planning Department provided approval for use of the PAF.

\section{Results}

\section{Description of study cohort}

Characteristics of the Pickering ( $\mathrm{n}=36$ 805), north Oshawa ( $\mathrm{n}=43$ 035) and Pickering non-mover cohorts ( $\mathrm{n}=10$ 084) are summarized in Table 1. Of note, the average annual household income in 1990 was significantly lower $\quad(\sim \$ 10 \quad 000$; $p<.0001$ ) and the average age at the beginning of follow-up for both sexes was significantly older $(\sim 3$ to 4 years; $p<.0001$ ) in north Oshawa compared to Pickering. Compared with all Pickering residents, the average age of Pickering non-movers at the beginning of follow-up for both sexes was significantly older. In addition, average annual household income was significantly lower $(\sim \$ 1500$; $p<.0001)$ among Pickering non-movers compared with all Pickering residents.

More than half of Pickering and all of north Oshawa residents experienced average tritium concentration levels below $2.9 \mathrm{~Bq} / \mathrm{m}^{3}$ (range: $0-14.74 \mathrm{~Bq} / \mathrm{m}^{3}$ ). This value is estimated to be an average effective dose of $0.47 \mu \mathrm{Sv} /$ year (range $0-2.36 \mu \mathrm{Sv} /$ year) for an average adult ${ }^{45}$ (assuming a radiological biological effectiveness of 1 and the dose coefficient recommended by the Canadian Nuclear Safety Commission, $2.0 \times 10^{-11} \mathrm{~Sv} / \mathrm{Bq}$ ), consistent with Ontario Power Generation dose estimates $^{22}$ and not registering on the low-dose range $(1-100 \mathrm{mSv}$, where $1 \mathrm{mSv}=1000 \mu \mathrm{Sv}) .{ }^{46}$ If the provisional radiological biological effectiveness value for tritium of 2 was used, ${ }^{6}$ dose estimates would be double that indicated but would still be far below the regulatory limit.

\section{Person-years analysis}

We observed little difference in SIRs across the four time periods for any of

\footnotetext{
* Point along the distribution of values for the independent variables where the nature of the relationship with the dependent variable is thought to change.
} 
TABLE 1

Characteristics of Pickering, north Oshawa and Pickering non-mover ${ }^{\mathrm{a}}$ cohorts, 1985

\begin{tabular}{|c|c|c|c|c|c|c|}
\hline & \multicolumn{6}{|c|}{ Population (n) } \\
\hline & \multicolumn{2}{|c|}{ All Pickering } & \multicolumn{2}{|c|}{ North Oshawa } & \multicolumn{2}{|c|}{ Pickering Non-movers ${ }^{a}$} \\
\hline & $\begin{array}{c}\text { Females } \\
(\mathrm{n}=18200)\end{array}$ & $\begin{array}{c}\text { Males } \\
(\mathrm{n}=18605)\end{array}$ & $\begin{array}{c}\text { Females } \\
(\mathrm{n}=21731)\end{array}$ & $\begin{array}{c}\text { Males } \\
(\mathrm{n}=21304)\end{array}$ & $\begin{array}{c}\text { Females } \\
(n=4845)\end{array}$ & $\begin{array}{c}\text { Males } \\
(n=5239)\end{array}$ \\
\hline Starting age, mean (SD) years & $31.84(16.50)$ & $31.58(16.25)$ & $35.73^{*}(19.03)$ & $34.55^{*}(18.55)$ & $35.14 *(17.74)$ & $34.41^{*}(17.60)$ \\
\hline \multicolumn{7}{|l|}{ Follow-up time in years, $\mathrm{n}(\%)$} \\
\hline$<1$ & $43(<1)$ & $53(<1)$ & $86(<1)$ & $92(<1)$ & $16(<1)$ & $19(<1)$ \\
\hline 1 to $<10$ & $502(3)$ & $599(3)$ & $985(5)$ & $1217(6)$ & $183(4)$ & $243(5)$ \\
\hline 10 to $<20$ & $815(4)$ & $1012(5)$ & $1503(7)$ & $1652(8)$ & $293(6)$ & $435(8)$ \\
\hline 20 & $16840(93)$ & $16941(91)$ & $19157(88)$ & $18343(86)$ & $4353(90)$ & $4561(87)$ \\
\hline 1990 Average EA income ${ }^{b}$, S (SD) & 67000 (13 395) & 67050 (13 279) & $56732 *(15525)$ & $57507^{*}(15403)$ & $65488^{*}(12524)$ & $65238^{*}(12876)$ \\
\hline \multicolumn{7}{|l|}{1990 Average EA income ${ }^{b}, \mathrm{n}(\%)$} \\
\hline$\$ 0-\$ 64725^{c}$ & $8241(45)$ & $8391(45)$ & $17196(79)^{*}$ & $16557(78)^{*}$ & $2424(50)^{*}$ & $2666(51)^{*}$ \\
\hline$\$ 64726-\$ 115015^{d}$ & $9959(55)$ & $10214(55)$ & $4535(21)^{*}$ & $4747(22)^{*}$ & $2421(50)^{*}$ & $2573(49)^{*}$ \\
\hline \multicolumn{7}{|l|}{ Tritium dispersion in $\mathrm{Bq} / \mathrm{m}^{3}, \mathrm{n}(\%)$} \\
\hline$\geq 2.9^{\mathrm{d}}$ & 7127 (39) & 7268 (39) & $0(0)^{*}$ & $0(0)^{*}$ & $2645(55)^{*}$ & $2851(55)^{*}$ \\
\hline$<2.9^{c}$ & $11073(61)$ & $11337(61)$ & $21731(100)^{*}$ & $21304(100)^{*}$ & $2200(45)^{*}$ & $2388(46)^{*}$ \\
\hline
\end{tabular}

Abbreviations: EA, enumeration area; SD, standard deviation.

a Resident at the same address in 1979.

b Source: Census of Canada, 1991. ${ }^{28}$

c Below average.

d Above average.

${ }^{*} p<.05$ compared with All Pickering and same sex mean or proportion; significance tests not conducted for follow-up time.

the cancer sites for Pickering, Pickering non-mover or north Oshawa residents. As a result, we reported only results across the whole time period (1986-2005) (see Table 2).

In Pickering the observed number of cases for the majority of cancer sites examined was significantly lower than expected across the entire time period. However, the observed number of female childhood cancers was significantly higher than expected (SIR $=1.99,95 \%$ CI: $1.08-3.38)$.

None of the SIRs among all Pickering nonmovers and north Oshawa residents were significantly elevated across the entire time period.

\section{Cox models}

The models comparing Pickering to north Oshawa (Table 3) reveal a significantly higher risk of female lung cancer in the Pickering cohort compared with the north Oshawa cohort $(\mathrm{HR}=2.34 ; 95 \% \mathrm{CI}$ : 1.23-4.46) after adjusting for modelled tritium dispersion, average household income and frailty. Of note, there was no evidence that tritium exposure was significantly associated with the risk of female lung cancer $\left(<2.9 \mathrm{~Bq} / \mathrm{m}^{3}\right.$ : $\mathrm{HR}=$ 0.56, 95\% CI: 0.21-1.48; $\geq 2.9 \mathrm{~Bq} / \mathrm{m}^{3}$ : $\mathrm{HR}=1.00$, CI: 0.39-2.55). An increase of $\$ 10000$ in average household income was associated with a significant $33 \%$ reduction in female lung cancer risk among those with below average household income $(\mathrm{HR}=0.67,95 \% \mathrm{CI}$ : 0.55-0.82).

There was no significant difference in the risk of male lung cancer $(\mathrm{HR}=0.93,95 \%$ CI: $0.53-1.66)$ or female breast cancer $(\mathrm{HR}=1.20,95 \% \mathrm{CI}: 0.82-1.77)$ between Pickering and north Oshawa residents. There was a significant $20 \%$ reduction in male lung cancer risk for every $\$ 10000$ increase in household income, irrespective of average neighbourhood household incomes. Frailty in these models indicated non-significant clustering of cancer risk at the census tract level. No significant interactions were found.

In the Cox models limited to Pickering non-movers, tritium had no significant effect on male and female lung cancer risk and female breast cancer risk (results available from the authors on request). Average household income, frailty and interactions were non-significant in all models.

\section{Discussion}

Person-years analysis of this retrospective cohort does not provide sufficient evidence for significantly elevated risks of cancer in Pickering, Ontario. For all Pickering residents, Pickering non-movers and north Oshawa residents, 19 of 33 categories of observed cancer cases were, in fact, significantly lower than expected. The one exception was female childhood cancers (all types combined, for 6-19 years) where the observed number of cases in Pickering was significantly higher than expected. However, this should be interpreted with caution for several reasons. First, radiation-induced cancer risks do not differ for boys and girls, yet there was no increased risk among boys. Second, the small expected value of 6 suggests this finding could be 


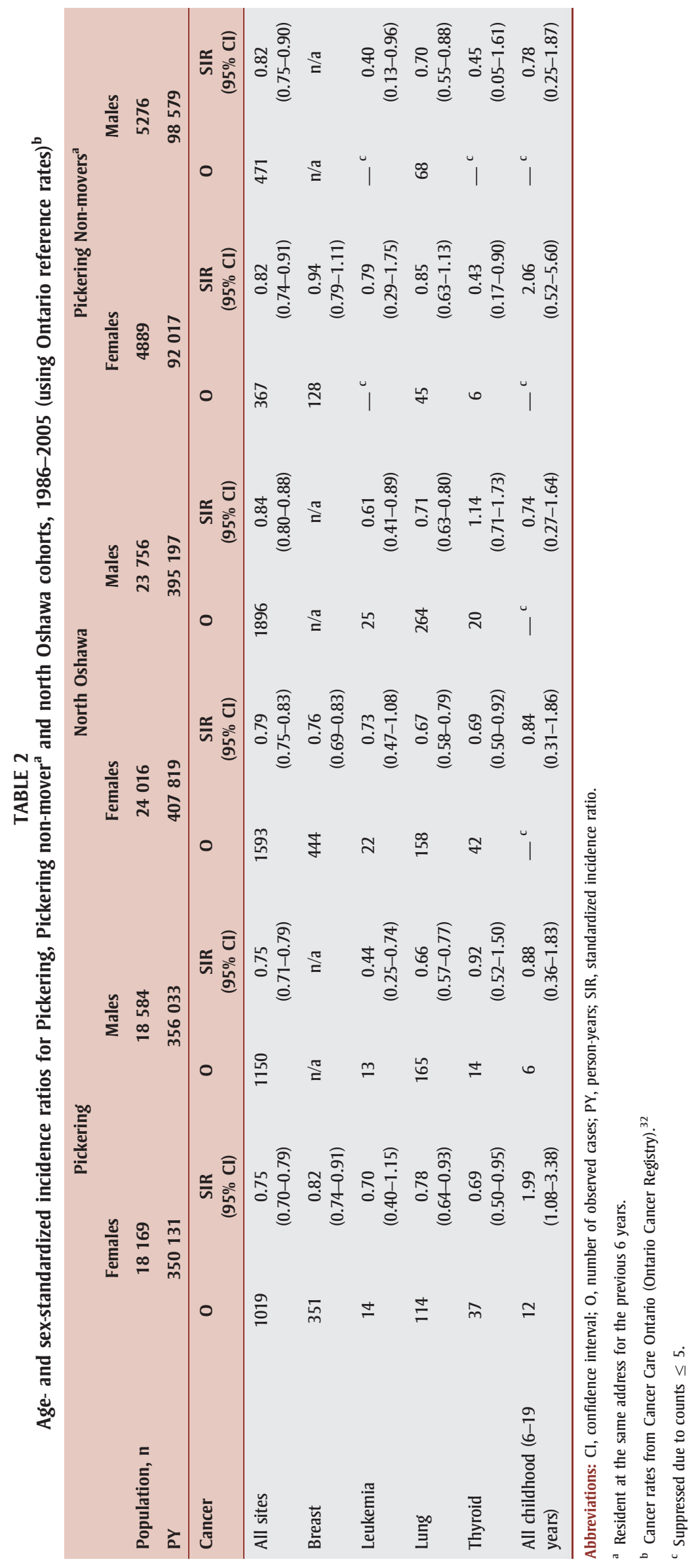

due to chance. Third, in this analysis we simultaneously conducted 33 hypothesis tests and under these conditions there is a large statistical probability that one test will be significantly higher than expected by chance alone. We believe this issue of multiple comparisons is the most likely explanation of the increased risk in female childhood cancers. We also examined the observed number of cases for individual cancer sites in this age group and found none were higher than expected. In addition, the cancer site with the largest observed count has no association with ionizing radiation. We also note that the studies conducted in Germany ${ }^{10,11}$ found elevated risk of childhood leukemia in the under-five age group, which is younger than the age group in this study.

The Cox models did not provide evidence of a statistically significant association between tritium emissions originating from PNGS and cancer risk.

The Cox models did show that risk of female lung cancer is over twice as high among Pickering residents compared with north Oshawa residents; however, tritium estimates do not significantly contribute to this risk. It is estimated that more than $85 \%$ of lung cancers in Canada are related to smoking ${ }^{47}-32 \%$ of Canadian women were reported to be daily smokers in $1981^{48}$ — and we did not have information on individual or small area level smoking estimates to adjust for this in our analyses. We did adjust for smoking in Cox models using average household income as a proxy; however, this may have been insufficient. It is possible that there was substantial disparity in smoking prevalence as well as other confounders and period or cohort effects between Pickering and north Oshawa residents in the 1970s and 1980s that we were unable to estimate and adjust for and that could have contributed to the difference in female lung cancer risk seen here.

Using Pickering non-movers in a separate Cox model was the best method available to control for potential migration of cohort members and the effect of this on tritium exposure estimates. However, these analyses were adequately powered to detect only very large differences in risk, which 
TABLE 3

Cox models for Pickering versus north Oshawa residents for female and male lung cancer, and female breast cancer

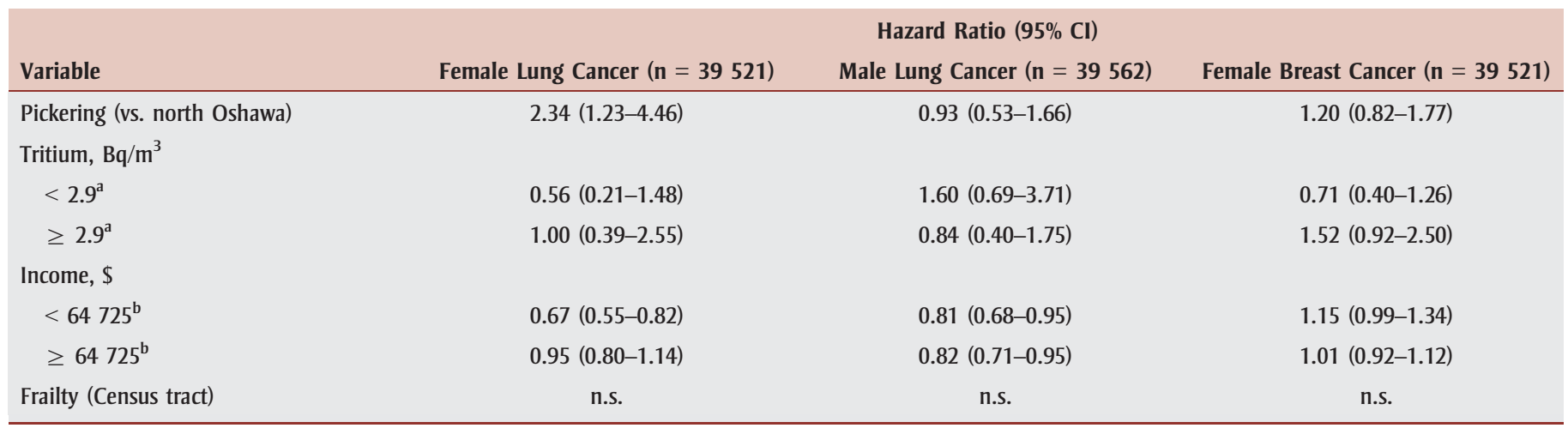

Abbreviations: $\mathrm{Cl}$, confidence interval; n.s., non-significant

${ }^{a}$ Change-point at the average tritium concentration. Interpret as per unit increase in tritium.

b A square root transformation was applied, income was standardized and change-point made at the average income for Pickering. Interpret per $\$ 10000$ increase in average income.

would not be expected from low levels of tritium exposure.

The number of research studies examining cancer risks in relation to CANDU reactors and other HWRS are limited. McLaughlin et al. ${ }^{49}$ and Clarke et al. ${ }^{50,51}$ examined risk of childhood leukemia around PNGS and a nuclear-generating station in Bruce County (also in Ontario) in a crosssectional study. They found elevated but non-significant risks among children born within $25 \mathrm{~km}$ and among children whose mothers lived within $25 \mathrm{~km}$ of either plant. ${ }^{49,50,51}$ In 2007, Durham Region Health Department released a surveillance report that examined cancer incidence in Ajax-Pickering (Ajax is a municipality adjacent to Pickering) compared with that of two nearby regions with no nuclear facilities, over two time periods. ${ }^{52}$ This report found that female breast, lung, thyroid, leukemia and childhood cancer risks were not consistently higher in AjaxPickering compared with reference areas. $^{52}$ The results of our cohort study are consistent with these findings.

In terms of occupational studies related to CANDU nuclear reactors, Zablotska et al. $^{53}$ found significant excess relative risks (but with wide-ranging CIs) for leukemia and all solid tumours combined. However, the authors indicated that it was possible that these results were due to chance. Concerns about the data prompted a reanalysis $^{54}$ and no increased cancer risk was found. McLaughlin et al. ${ }^{55}$ found that childhood leukemia was not associated with paternal occupational radiation exposure. Potentially important confounders were unavailable to use for adjustment in all studies.

\section{Strengths}

The cohort design we used in our study permitted explicit consideration of the long latency period of cancer by enabling follow-up of cohort members for a period of time (about 20 years) sufficient for most cancers to develop.

We were able to adjust for income in our Cox models whereas the studies mentioned $^{49-55}$ above did not. We were also able to identify non-moving Pickering residents to further isolate a subpopulation of the cohort that likely had more stable tritium exposure.

Ours appears to be the only populationbased epidemiological study examining risks from any type of nuclear power plant that used formal estimates of tritium concentrations in the environment-an important strength. All previous studies around CANDU reactors assumed tritium exposure by proximity alone.

Better aligned data not being available, there is some misalignment of dates for data sources used in tritium estimation. The impact of this on the validity of these tritium estimates is, however, minimal. Long-term meteorological data are rela- tively constant over many years, and thus the estimated exposure gradient would be similar over many years both before and after the period of the data source (1996-2000). In terms of the tritium emissions and facility characteristics used in this study (1994-1998), historical data show that the quantity of annual tritium emissions has been relatively consistent since the mid-1970s. ${ }^{3,56}$

There are marked differences between onsite meteorology at PNGS and meteorology observed at Toronto Pearson International Airport. However, when predicted model estimates using either meteorology are compared with observed tritium concentrations for a number of onsite monitors, predicted model estimates were quite similar to each other and higher than concentrations observed by on-site monitors. ${ }^{57}$

\section{Limitations}

We are reasonably confident that our tritium estimates are appropriate given that modelled estimates closely align with on-site monitors. However, we are less confident that these ecological estimates represent true dose for cohort members because we could not reconstruct personal activity patterns or consider other sources of radiation exposure. We could have made assumptions to reconstruct the dose; however, this would add little value to these analyses because assumptions would be uniformly applied across the 
cohort and would not change the distribution of exposure among cohort members.

This inability to assign individual exposure accurately can lead to measurement error. ${ }^{58}$ Considering the wide CIs around these tritium risk estimates and the large sample sizes in the Pickering versus north Oshawa analyses, potential misclassification of tritium would not likely change the interpretation of its contribution to cancer risk.

Loss-to-follow-up is a potential bias that may affect the results. Potential loss-tofollow-up due to name changes was minimized because alternative names were available in the OCR. There was $88 \%$ agreement between two record linkage analysts working independently to review uncertain matches. It is also possible that loss-to-follow-up occurred through emigration from Ontario. As long as cohort members remained in Ontario, there is reasonable certainty that cancer and mortality information were captured by the probabilistic linkages. Unfortunately, no estimate of emigration from the study area is available. The bias caused by migration is not well understood. ${ }^{59}$

\section{Future studies}

Future studies would benefit from using a larger retrospective cohort to examine rare cancers. In addition, reconstruction of personal dose estimates using knowledge of other sources of radiation exposure, residential history and activity patterns would be useful.

\section{Conclusion}

We did not find increased risk of cancer associated with tritium exposure from PNGS. Improving the validity of individual tritium exposure estimates is crucial to allay public concern. The use of a retrospective cohort with sufficient follow-up time, a large sample size and tritium estimation in this study are substantial methodological improvements. This study increases our understanding of cancer risks and low level tritium exposure.

\section{Acknowledgements}

We gratefully acknowledge the assistance of the Durham Region Planning Department and the help of Lars Jarup, Linda Beale, Juanjo Abellan and Mattias Andersson, all formerly of the Small Area Health Statistics Unit, at Imperial College London; Doug Chambers, Ron Stager and Zivorad Radonjic of SENES Consulting (Richmond Hill, Ontario); and Cancer Care Ontario and the U.S. Centers for Disease Control and Prevention, Environmental Public Health Tracking Branch. We particularly thank Karen Hoffman, at Cancer Care Ontario, for help with record linkage.

Financial support: We received financial support from GeoConnections, a national program initiative led by Natural Resources Canada. GeoConnections is working to enhance the Canadian Geospatial Data Infrastructure, an online resource that enables decision-makers to access, combine and apply geographic information to gain new insights into social, environmental and economic issues.

\section{Conflict of interest: None.}

\section{References}

1. Innovative Research Group, Inc. 2012 public opinion research - national nuclear attitude survey [Internet]. Ottawa (ON): Canadian Nuclear Association; 2012 [cited 2012 Jul 19]. Available from: http://www .cna.ca/wp-content/uploads/2012Nuclear AttitudeReport.pdf

2. Wakeford R. The cancer epidemiology of radiation. Oncogene. 2004;23(38):6404-28.

3. Canadian Nuclear Safety Commission. Health effects, dosimetry and radiological protection of tritium: part of the Tritium Studies Project [Internet]. Ottawa (ON): CNSC; 2010 [cited 2011 Oct 26]. Available from: http://www.nuclearsafety.gc.ca/pubs _catalogue/uploads/CNSC_Health_Effects _Eng-web.pdf
4. Report of the Committee Examining Radiation Risks of Internal Emitters (CERRIE) [Internet]. London (UK): CERRIE; 2004 [cited 2013 Jan 30]. Available from: http://www.rachel.org/lib /cerrie_report.041015.pdf

5. Little MP, Wakeford R. Systematic review of epidemiological studies of exposure to tritium. J Radiol Prot. 2008;28:9.

6. Health Protection Agency. Review of risks from tritium: report of the independent Advisory Group on Ionising Radiation [Internet]. London (UK): HPA Radiation Protection Division; 2007 [cited 2013 Jan 23]. Available from: http://www.hpa .org.uk/webc/HPAwebFile/HPAweb_C /1197382221858

7. Laurier D, Bard D. Epidemiologic studies of leukemia among persons under 25 years of age living near nuclear sites. Epidemiol Rev. 1999;21(2):188-206.

8. Laurier D, Grosche B, Hall P. Risk of childhood leukaemia in the vicinity of nuclear installations--findings and recent controversies. Acta Oncol. 2002;41(1): 14-24.

9. Laurier D, Jacob S, Bernier $\mathrm{M}$, et al. Epidemiological studies of leukaemia in children and young adults around nuclear facilities: a critical review. Radiat Prot Dosimetry. 2008;132(2):182-90.

10. Kaatsch P, Spix C, Schulze-Rath R, Schmiedel S, Blettner M. Leukaemia in young children living in the vicinity of German nuclear power plants. Intl J Cancer. 2008 Feb 15;122(4):721-6.

11. Spix C, Schmiedel S, Kaatsch P, SchulzeRath R, Blettner M. Case-control study on childhood cancer in the vicinity of nuclear power plants in Germany 1980-2003. Eur J Cancer. 2008 Jan;44(2):275-84.

12. Commission on Radiological Protection (SSK). Assessment of the epidemiological study on childhood cancer in the vicinity of nuclear power plants (KiKK Study) [Internet]. Bonn (DE): Strahlenschutzkommission; 2008 Sep [cited 2013 Jan 28]. Available from: http://www.ssk.de/Shared Docs/Beratungsergebnisse_PDF/2008/Kikk _Studie_e.pdf?__blob= publicationFile 
13. Laurier D, Hémon D, Clavel J. Childhood leukaemia incidence below the age of 5 years near French nuclear power plants. J Radiol Prot. 2008 Sep;28(3):401-3.

14. Sermage-Faure C, Laurier D, Goujon-Bellec $\mathrm{S}$, et al. Childhood leukemia around French nuclear power plants--the Geocap study, 2002-2007. Int J Cancer. 2012 Sep 1;131(5):769-80.

15. Bithell JF, Keegan TJ, Kroll ME, Murphy MF, Vincent TJ. Childhood leukaemia near British nuclear installations: methodological issues and recent results. Radiat Prot Dosimetry. 2008;132(2):191-7.

16. Heinavaara S, Toikkanen S, Pasanen K, Verkasalo PK, Kurttio P, Auvinen A. Cancer incidence in the vicinity of Finnish nuclear power plants: an emphasis on childhood leukemia. Cancer Causes Control. 2010;21(4):587-95.

17. Government of Canada SC. Statistics Canada: 2006 Community Profiles [Internet]. 2007 [cited 2013 Jan 28]. Available from: http://www12.statcan.gc .ca/census-recensement/2006/dp-pd/prof /92-591/details/Page.cfm?Lang = E\&Geo1 $=$ CSD $\&$ Code $1=3518001 \&$ Geo $2=$ PR\&Code 2 $=35 \&$ Data $=$ Count $\&$ SearchText $=$ pickering \&SearchType $=$ Begins $\&$ SearchPR $=01 \&$ B 1 $=$ All\&Custom $=$

18. International Atomic Energy Agency. Heavy water reactors: status and projected development [Internet]. Vienna (AT): International Atomic Energy Agency; 2002 Apr [cited 2013 Jan 28]. Technical reports series no. 407. Available from: http://www -pub.iaea.org/MTCD/publications/PDF /TRS407_scr/D407_scr1.pdf

19. United Nations Scientific Committee on the Effects of Atomic Radiation. Sources and effects of ionizing radiation. UNSCEAR 2008 report to the General Assembly with Scientific Annexes. Volume 1 [Internet]. New York (NY): United Nations; 2010 [cited 2013 Jan 28]. Available from: http: //www.unscear.org/docs/reports/2008/09 -86753_Report_2008_Annex_B.pdf
20. Canadian Nuclear Safety Commission. Investigation of the environmental fate of tritium in the atmosphere: Part of the Tritium Studies Project [Internet]. Ottawa (ON): CNSC; 2010 [cited 2012 July 19]. Available from: http://nuclearsafety.gc.ca /pubs_catalogue/uploads/Investigation _of_Environmental_Fate_of_Tritium_in_the _Atmosphere_INFO-0792_e.pdf

21. Ontario Power Generation. 2006 results of radiological environmental monitoring programs [Internet]. Toronto (ON): Ontario Power Generation: 2006 [cited 2013 Jan 28]. Available from: http://www.opg .com/pdf/Nuclear \%20Reports \% 20and \% 20 Publications/2006\% 20Radiological \% 20 Environmental\%20Monitoring\%20Program \%20\%28REMP\%29\%20Report.pdf

22. Ontario Power Generation. 2011 results of radiological environmental monitoring programs [Internet]. Toronto (ON): Ontario Power Generation; 2012 [cited 2013 Jan 28]. Available from: http://www.opg .com/pdf/Nuclear \% 20Reports \% 20and \% 20 Publications/2011\%20Radiological \% 20 Environmental \%20Monitoring \%20Program \%20\%28REMP\%29\%20Report.pdf

23. Holowaty EJ, Chong N. The Ontario cancer registry: a registry with almost complete automated data collection. In: Black RJ, Simonato L, Storm H, editors. Automated data collection in cancer registry, IARC technical reports, No. 32. Lyon (FR): IARC Press; 1998:18(32).

24. Jaro M. Probabilistic linkage of large public health data files. Stat Med. 1995;14:491-8.

25. Brenner DJ, Doll R, Goodhead DT, et al. Cancer risks attributable to low doses of ionizing radiation: Assessing what we really know. Proc Natl Acad Sci U.S.A. 2003;100(24):13761-6.

26. Health Analytics Branch. Health analyst's toolkit [Internet]. Toronto (ON): Ontario Ministry of Health and Long-Term Care; 2012 [cited 2013 Jan 10]. Available from: http://www.health.gov.on.ca/english /providers/pub/healthanalytics/health _toolkit/health_toolkit.pdf
27. AERMOD Implementation Workgroup. AERMOD implementation guide [Internet]. Atlanta (GA): U.S. Environmental Protection Agency. 2009 Mar [cited 2013 Jan 28]. Available from: http://www.epa.gov/scram 001/7thconf/aermod/aermod_implmtn_guide _19March2009.pdf

28. Schaap MM, Kunst AE. Monitoring of socioeconomic inequalities in smoking: learning from the experiences of recent scientific studies. Public Health. 2009;123(2):103-9.

29. Statistics Canada. Census of Canada, 1991: profile of enumeration area - part B (B9105) [Internet]. Ottawa (ON): Statistics Canada; [cited 2011 October 11]. Available from: http://prod.library.utoronto.ca:8090/datalib /codebooks/c/cc91/profilea/b9105.reclay

30. Szklo M, Nieto J. Epidemiology: beyond the basics. 2nd ed. Burlington (MA): Jones and Bartlett Publishers; 2006.

31. Carstensen B. Lexis: a SAS-macro for splitting follow-up time [Internet]. Copenhagen (DK): University of Copenhagen; 1999 [cited 2011 Oct 18]. Available from: http://bendixcarstensen .com/Lexis/Lexis.sas

32. Cancer Care Ontario (Ontario Cancer Registry). SEER*Stat Release - OCRIS.

33. Breslow NE, Day NE, editors. Statistical methods in cancer research: volume II: the design and analysis of cohort studies. IARC Scientific Publications No. 82. Lyon (FR): IARC; 1994.

34. Fleiss JL, Levin B, Paik MC, Fleiss J. Statistical methods for rates and proportions. 3rd ed. Hoboken (NJ): Wiley-Interscience; 2003.

35. Cox D. Regression models and life-tables. J R Stat Soc Ser B Stat Methodol. 1972; 34(2):187-220.

36. Allison PD. Survival analysis using SAS: a practical guide. Cary (NC): SAS Publishing; 1995.

37. Brown P, Jiang H. Simulation-based power calculations for large cohort studies. Biom J. 2010;52(5):604-15.

38. Thiebaut AC, Benichou J. Choice of timescale in Cox's model analysis of epidemiologic cohort data: a simulation study. Stat Med. 2004;23:3803-20. 
39. Commenges D, Letenneur L, Joly P, Alioum A, Dartigues JF. Modelling age-specific risk: application to dementia. Stat Med. 1998;17(17):1973-88.

40. Kom EL, Graubard BI, Midthune D. Timeto-event analysis of longitudinal follow-up of a survey: choice of the time-scale. Am J Epidemiol. 1997;145(1):72-80.

41. Canchola AJ, Stewart SL, Bernstein L, et al. Cox regression using different time-scales [Internet]. Western Users of SAS Software, 2008 Conference; [cited 2011 Oct 31]. Available from: http://www.lexjansen .com/wuss/2003/DataAnalysis/i-cox_time _scales.pdf

42. Vittinghoff E, Glidden DV, Shiboski SC, McCulloch CE. Regression methods in biostatistics: linear, logistic, survival, and repeated measures models. New York (NY): Springer; 2005.

43. Hosmer DW Jr, Lemeshow S, May S. Applied survival analysis: regression modeling of time to event data. 2nd ed. Hoboken (NJ): Wiley-Interscience; 2008.

44. Banerjee S, Wall MM, Carlin BP. Frailty modeling for spatially correlated survival data, with application to infant mortality in Minnesota. Biostatistics. 2003 Jan;4(1): 123-42.

45. Age-dependent dose to members of the public from intake of radionuclides: Part 5. Compilation of ingestion and inhalation dose coefficients. Ann ICRP. 1996 Jan;26(1):1-91.

46. Gilbert ES. Ionising radiation and cancer risks: what have we learned from epidemiology? Int J Radiat Biol. 2009;85(6): 467-82.

47. Canadian Cancer Society. Smoking and cancer [Internet]. Toronto (ON): Canadian Cancer Society; 2013 [cited 2013 May 24]. Available from: http://www.cancer.ca /en/prevention-and-screening/live-well $/$ smoking-and-tobacco/?region $=$ on
48. Stephens T. A critical review of Canadian survey data on tobacco use, attitudes and knowledge [Internet]. Ottawa (ON): Tobacco Programs Unit, Health Promotion Directorate, Health and Welfare Canada; 1988 Apr [cited 2012 Jul 19]. Available from: http://tobaccodocuments.org/nysa _ti_s2/TI14132323.html

49. McLaughlin JR, Clarke EA, Nishri ED, Anderson TW. Childhood leukemia in the vicinity of Canadian nuclear facilities. Cancer Causes Control. 1993;4(1):51-8.

50. Clarke EA, McLaughlin J, Anderson TW. Childhood leukemia around Canadian nuclear facilities - phase I: final report [Internet]. Ottawa (ON): Atomic Energy Control Board; 1989 May [cited 2012 Jul 19]. Available from: http://www.nuclearsafety .gc.ca/eng/about/past/timeline-dev/resources /documents/infohistorical/info-0300-1.pdf

51. Clarke EA, McLaughlin J, Anderson TW. Childhood leukemia around Canadian nuclear facilities - phase II: final report [Internet]. Ottawa (ON): Atomic Energy Control Board; 1991 Jun [cited 2012 Jul 19]. Available from: http://www.nuclearsafety.gc.ca/eng/about /past/timeline-dev/resources/documents /infohistorical/info-0300-2.pdf

52. Durham Region Health Department. Radiation and health in Durham region [Internet]. Whitby (ON): Durham Region Health Department; 2007 [cited 2012 June 27]. Available from: http://www.durham .ca/departments/health/health_statistics /radiationHealthReport2007.pdf

53. Zablotska LB, Ashmore JP, Howe GR. Analysis of mortality among Canadian nuclear power industry workers after chronic low-dose exposure to ionizing radiation. Radiat Res. 2004;161(6):633-41.

54. Canadian Nuclear Safety Commission. Verifying Canadian nuclear energy worker radiation risk: a reanalysis of cancer mortality in Canadian nuclear energy workers (1957-1994) Summary report INFO-0811 [Internet]. Ottawa (ON): CNSC; 2011 Jun [cited 2013 Jan 30]. Available from: http:// www.nuclearsafety.gc.ca/pubs_catalogue /uploads/INFO-0811-Verifying-CanadianNuclear-Energy-Worker-Radiation-Risk-AReanalysis-of-Cancer-Mortality-in-CanadianNuclear-Energy-Workers-1957-1994_e.pdf
55. McLaughlin JR, King WD, Anderson TW, Clarke EA, Ashmore JP. Paternal radiation exposure and leukaemia in offspring: the Ontario case-control study. BMJ. 1993;307(6910):959-66.

56. United Nations Scientific Committee on the Effects of Atomic Radiation. UNSCEAR 1988 Report Sources, Effects and Risks of Ionizing Radiation -Annex B: Exposures from nuclear power production [Internet]. New York: United Nations;1988 [cited 2012 July 19]. Available from: http://www.unscear .org/docs/reports/1988/1988e-f_unscear.pdf

57. SENES Consultants Limited. Air dispersion modeling in support of the Ontario Health and Environment Integrated Surveillance (OHEIS) project. Richmond Hill (ON): SENES Consulting; 2009.

58. Nuckols JR, Ward MH, Jarup L. Using geographic information systems for exposure assessment in environmental epidemiology studies. Environ Health Perspect. 2004;112:1007-15.

59. Hatch M, Thomas D. Measurement issues in environmental epidemiology. Environ Health Perpect. 1993;101(Suppl 4):49-57. 